\title{
Alterations of Membrane Lipid Content Correlated With Chloroplast and Mitochondria Development in Euglena gracilis
}

\author{
Shiori Shibata ${ }^{1}$, Shin-ichi Arimura2,3, Takahiro Ishikawa ${ }^{4,5}$ and Koichiro Awai 1,5,6* \\ 1 Graduate School of Integrated Science and Technology, Shizuoka University, Shizuoka, Japan, ${ }^{2}$ Graduate School of \\ Agricultural and Life Sciences, The University of Tokyo, Tokyo, Japan, ${ }^{3}$ Precursory Research for Embryonic Science and \\ Technology, Japan Science and Technology Agency, Saitama, Japan, ${ }^{4}$ Department of Life Science and Biotechnology, \\ Faculty of Life and Environmental Science, Shimane University, Matsue, Japan, ${ }^{5}$ Core Research for Evolutional Science and \\ Technology, Japan Science and Technology Agency, Tokyo, Japan, ${ }^{6}$ Research Institute of Electronics, Shizuoka University, \\ Hamamatsu, Japan
}

\section{OPEN ACCESS}

Edited by:

Rebecca L. Roston, University of Nebraska-Lincoln,

United States

Reviewed by:

Yonghua Li-Beisson,

Commissariat à l'Energie Atomique et aux Energies Alternatives (CEA),

France

Wayne Riekhof University of Nebraska-Lincoln, United States

${ }^{*}$ Correspondence: Koichiro Awai awai.koichiro@shizuoka.ac.jp

Specialty section: This article was submitted to

Plant Cell Biology,

a section of the journal

Frontiers in Plant Science

Received: 30 November 2017 Accepted: 06 March 2018 Published: 27 March 2018

Citation:

Shibata S, Arimura S-i, Ishikawa T and Awai K (2018) Alterations

of Membrane Lipid Content

Correlated With Chloroplast and Mitochondria Development in Euglena gracilis.

Front. Plant Sci. 9:370. doi: 10.3389/fpls.2018.00370
Euglenoids are unique protists that can grow photoautotrophically, photomixotrophically, and heterotrophically. Here we grew Euglena gracilis under these different growth conditions and determined cellular contents of seven membrane lipids and one storage lipid (triacylglycerol), which account for more than 94 mol\% of total membrane lipids. We also describe the relationship among chloroplast and mitochondria developments with lipid contents, protein contents, and oxygen evolution/consumption rates. In photoautotrophic growth conditions, E. gracilis cells accumulated chlorophyll, photosynthetic proteins, and glycolipids typical to thylakoid membranes. The same occurred for the cells grown under photomixotrophic conditions with higher respiration rates. In heterotrophic conditions, E. gracilis cells had higher respiration rates compared to cells grown in other conditions with the accumulation of pyruvate: NADP+ oxidoreductase, a mitochondrial protein and phospholipid common in mitochondria. Cells were also observed using a confocal laser scanning microscope and found to show more chlorophyll autofluorescence when grown photoautotrophically and photomixotrophycally, and fluorescence of MitoTracker when grown photomixotrophically and heterotrophically. These results suggest that under illumination, E. gracilis develops functional thylakoid membranes with membrane lipids and proteins for photosynthesis. In the medium with glucose, the cells develop mitochondria with phospholipids and proteins for respiration. Possible application based on lipid analysis for the enhancement of wax ester or alkene synthesis is discussed.

Keywords: Euglena gracilis, membrane lipids, photosynthesis, respiration, thylakoid membranes, MitoTracker, confocal laser scanning microscopy

\section{INTRODUCTION}

Euglenoids are unicellular photosynthetic protists mostly found in freshwater, such as lakes, ponds, and rivers. Euglenoids are believed to acquire chloroplasts by secondary endosymbiosis with the alga that shares a common ancestor with current green algae (Gibbs, 1978; McFadden, 2001). Euglenoids are uniquely able to grow photoautotrophically, photomixotrophically, and 
heterotrophically. According to this feature, these organisms have been used for analysis of chloroplast development, especially in the model euglenoid Euglena gracilis. Since E. gracilis can grow heterotrophically, chloroplast development has been analyzed by illuminating dark-grown cells. When the E. gracilis cells transform from dark-heterotrophic to light-photoautotrophic growth, the cells start developing chloroplasts. E. gracilis cells are known to accumulate a storage carbohydrate, paramylon ( $\beta$-1,3-glucose polymer) under heterotrophic growth conditions (Schwartzbach et al., 1975; Inui et al., 1982), and they utilize it during chloroplast development for synthesis of proteins, nucleic acids, and membrane lipids (Rosenberg and Pecker, 1964; Schiff and Schwartzbach, 1982; Osafune et al., 1990; Sumida et al., 2007). Light-grown cells have also been placed in the dark and analyzed for degradation of chloroplasts (Scheer and Parthier, 1982; Ferroni et al., 2009). These studies report the morphology of chloroplasts; content of photosynthetic proteins, pigments, and membrane lipids; and degradation of paramylon. However, there are few reports describing the relationship between membrane lipid composition and cell specialization in E. gracilis.

In E. gracilis, a wax ester, a type of storage lipid, is well analyzed for potential use as a biofuel (Inui et al., 1982, 1984, 2017). This wax ester is mainly composed of C14:0 saturated fatty acid, myristic acid, and myristyl alcohol (Hulanicka et al., 1964). It is known to accumulate especially under hypoxic conditions by consuming the paramylon to obtain energy without respiration (Inui et al., 1982). Both wax ester and membrane lipids are made from fatty acids, there are not much information on membrane lipids of E. gracilis. Early reports described the lipid metabolism (Hulanicka et al., 1964) and the effect of light intensity on lipid composition (Constantopoulos and Bloch, 1967), but these reports mainly analyzed fatty acid composition and only described membrane lipids as the sums of polar lipids or phospholipids. Some reports describe the membrane lipid composition of E. gracilis, especially thylakoid glycolipids monogalactosyldiacylglycerol (MGDG), digalactosyldiacylglycerol (DGDG) and sulfoquinovosyldiacylglycerol (SQDG) (Rosenberg, 1963; Rosenberg and Pecker, 1964; Rosenberg et al., 1966). More recently, comprehensive analyses of membrane lipids were done with classical (Regnault et al., 1995) or more advanced techniques (LC-MS/MS) (Ogawa et al., 2014). The former one reports only five membrane lipids including MGDG, DGDG, phosphatidylglycerol (PG), phosphatidylcholine (PC), and phosphatidylethanolamine (PE). The latter one showed unusual lipid contents (lacking DGDG and SQDG with a very high content of sphingomyelin). Phosophatidylinositol (PI) is also described as a minor component in some reports (Calvayrac and Douce, 1970; Fujita et al., 1995). Therefore, more detailed analyses of lipid compositions of E. gracilis are needed.

In this article, we present comprehensive analysis of lipids in E. gracilis by a combination of traditional TLC-based methods with LC-MS/MS. Based on this, we analyzed the relationship between membrane lipid contents and chloroplast/mitochondria developments with oxygen evolution/consumption rates, quantum efficiency of photosystem II (PSII), amounts of chloroplastic/mitochondrial proteins, and a confocal laser scanning microscopy.

\section{MATERIALS AND METHODS}

\section{Growth Conditions}

Euglena gracilis Z was cultured in 200-ml flasks containing $100 \mathrm{ml}$ of Cramer-Myers (CM) medium (Cramer and Myers, 1952) for photoautotrophic growth at $26^{\circ} \mathrm{C}$ under continuous light $\left(100 \mu \mathrm{mol} \cdot\right.$ photons $\mathrm{m}^{-2} \cdot \mathrm{s}^{-1}$ ) with rotary shaking at $120 \mathrm{rpm}$. For photomixotrophic growth, CM medium with $0.6 \%$ $(\mathrm{w} / \mathrm{v})$ glucose $(\mathrm{CM}+\mathrm{Glc})$ was used under the same conditions. For the heterotrophic growth, cells were cultured in $\mathrm{CM}+\mathrm{Glc}$ medium in the same condition, but the flasks were completely wrapped with aluminum foil. To obtain growth curves, algal cultures were diluted with fresh medium at an initial cell number of $3.0 \times 10^{3}$, and the cell number was counted using the Cellometer (Auto T4, Nexcelom, United States) every $24 \mathrm{~h}$.

\section{Chlorophyll Contents, Oxygen Evolution Rates, and Chlorophyll Fluorescence}

Chlorophyll content was measured as described (Arnon, 1949). The oxygen evolution rate of intact cells was measured with a Clark-type oxygen electrode (Hansatech Instruments Ltd.) and a LED lamp (CCS Inc., Kyoto, Japan). Chlorophyll fluorescence measurements were performed with a Dual-PAM system (Heinz Walz GmbH). PSII quantum efficiency was measured as (Fm-Fo)/Fm, where Fm is the maximum PSII fluorescence obtained with a red saturating pulse $(635 \mathrm{~nm}, 300 \mathrm{~ms}$ duration, 20,000 $\mu \mathrm{mol}$ photons $\mathrm{m}^{-2} \mathrm{~s}^{-1}$ ) and Fo is the minimum fluorescence obtained after $10 \mathrm{~min}$ of far red light (intensity setting 20) to ensure a state 1 transition.

\section{Protein Extraction, SDS-PAGE, and Western Blot Analysis}

For protein extraction, $2 \mathrm{ml}$ of culture $\left(\sim 1 \times 10^{6}\right.$ cells $)$ was centrifuged at $16,000 \times g$, and the precipitated cells were frozen with liquid nitrogen. These cells were lysed five times by a homogenizer (Micro Smash MS-100R, TOMY) at 2,000 rpm for $20 \mathrm{~s}$. Then the powdered cells were suspended in $200 \mu \mathrm{l}$ of the resuspend buffer [50 mM HEPES ( $\mathrm{pH} 7.0$ ), $25 \mathrm{mM}$ $\mathrm{CaCl}_{2}, 5 \mathrm{mM} \mathrm{MgCl}_{2}, 10 \%$ (v/v) glycerol, $1 \mathrm{mM} \mathrm{PMSF}$, and $5 \mathrm{mM}$ 6-aminocaproic acid] (Barthel et al., 2013) and used for Western blot analysis. For protein content analysis, aliquots of the suspended cells were mixed with the same volume of detergent solution [60 mM Tris-HCl (pH6.8), 2\% SDS (w/v)]. A BCA Protein Assay Kit (Thermo Fischer Scientific) was used with BSA as a standard.

Laemmli SDS-PAGE (Laemmli, 1970) was performed using polyacrylamide gels containing $10 \%(\mathrm{w} / \mathrm{v})$ acrylamide. Proteins from the same number of cells $\left(\sim 5 \times 10^{4}\right.$ cells $)$ were applied to each lane. Samples were mixed with loading buffer with $175 \mathrm{mM}$ DTT and not heat-denatured to avoid aggregation of membrane proteins. The gels were stained with Coomassie 
Brilliant Blue R-250 (CBB). Pre-stained Protein Markers (Broad Range) for SDS-PAGE (Nacalai Tesque) were used to calibrate the gels.

For immunodetection, rabbit antibodies against PsbC (AS111787, CP43), PsbO (AS06-142-33), and RbcL (AS03037) (Agrisera) were used at a 1:3,000 dilution. Polyclonal antibodies against spinach PsbA/D (a gift from Dr. Masahiko Ikeuchi at The University of Tokyo) and Euglena pyruvate: NADP+ oxidoreductase (PNO, a gift from Dr. Masami Nakazawa at Osaka Prefecture University) were used at the same dilution. These antibodies were detected with an anti-rabbit horseradish peroxidase-coupled antibody (ab97051, Abcam) at a dilution of 1:10,000 using Can Get Signal Immunoreaction Enhancer Solution (Toyobo) followed by development with Western Lightning Plus-ECL (Perkin Elmer).

\section{Fluorescence Microscopy}

Fluorescence microscopy was carried out as described (Nagaoka et al., 2017). Briefly, Euglena cells were stained with MitoTracker Orange CMTMRos (Life Technologies) for $30 \mathrm{~min}$ and washed five times with CM medium before observations by a fluorescent microscope (Nikon, ECLIPSE Ti) equipped with a confocal laser scanning microscope system (Nikon, C1Si).

\section{Lipid Analysis}

Lipids were extracted as described (Bligh and Dyer, 1959) and separated by TLC. For membrane lipid analysis, a solvent system of chloroform: methanol: petroleum ether: acetone: acetic acid: $\mathrm{H}_{2} \mathrm{O}$ (20: 15: 10: 5: 1.3: 1, v/v) (Suzuki et al., 2016) was used for initial separation. Then, detected spots were further separated by the solvent systems hexane: tetrahydrofuran: 2-propanol: $\mathrm{H}_{2} \mathrm{O}$ (50: 0.5: 35: 3, v/v) (Hölzl et al., 2005), chloroform: methanol: acetic acid: $\mathrm{H}_{2} \mathrm{O}$ (34: 5: 5: 0.8, v/v) (Nichols and James, 1964), or chloroform: methanol: $\mathrm{H}_{2} \mathrm{O}$ (65: 25: 4, v/v) (Allen et al., 1966). For neutral lipid analysis, a solvent system of hexane: diethyl ether: acetic acid (80: 20: 1 or 90: 15: 1, v/v) (Kalscheuer and Steinbuchel, 2003) was used.

Separated lipids were determined by TLC co-chromatographed with standard lipids and liquid chromatographymass spectrometry (LC-MS, Shimadzu LCMS-2010A system) as described (Okazaki et al., 2013).

For quantitative and qualitative analysis of fatty acids attached to lipids, each separated spot was scraped off and fatty acid methyl esters (FAMEs) were prepared. FAMEs were then analyzed by gas chromatography (GC) equipped with a flame ionization detector (FID) for quantitative analysis, and GC-mass spectrometry (MS) for qualitative analysis. GC-FID was carried out as described (Awai et al., 2014) with slight modification. Shimadzu GC2014 equipped with a FID on a capillary column (BPX90, $60 \mathrm{~m} \times 0.25 \mathrm{~mm}$, SGE Analytical Science) was used. The column temperature was gradually increased from $140^{\circ} \mathrm{C}$ to $240^{\circ} \mathrm{C}$ at a rate of $5^{\circ} \mathrm{C} / \mathrm{min}$. The injector and detector temperature were both $250^{\circ} \mathrm{C}$. The linear velocity of carrier gas $(\mathrm{He})$ was $25 \mathrm{~cm} / \mathrm{min}$. GC-MS was carried out using a Shimadzu GCMSQP2010SE under the same condition as GC-FID. The ion source temperature was set to $200^{\circ} \mathrm{C}$ and both the injection port and interface temperature were $250^{\circ} \mathrm{C}$.
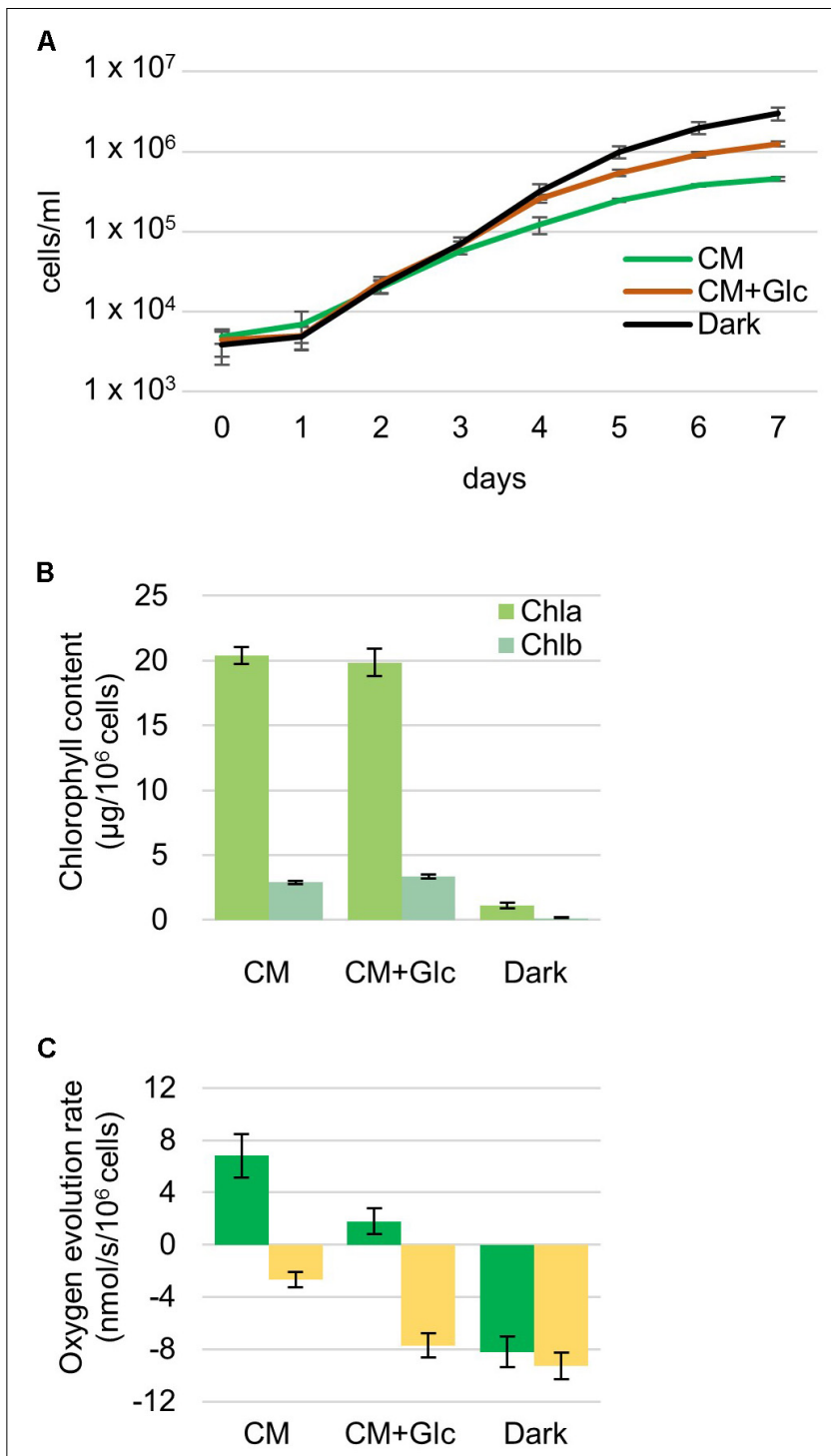

FIGURE 1 | Properties of Euglena cells grown under photoautotrophic, photomixotrophic and heterotrophic conditions. (A) Growth curve of the cells. Algal cultures were diluted with fresh medium at an initial cell number approximately 4,000 and grown for 7 days. Error bars indicate the SE based on six independent experiments. (B) Chlorophyll contents per $10^{6}$ cells. Error bars indicate the SE based on at least twelve independent experiments. (C) Oxygen evolution and consumption rates. Oxygen evolution rates were measured under the growth light intensity $\left(105 \mu \mathrm{mol}\right.$ photons $\left.\mathrm{m}^{-2} \cdot \mathrm{s}^{-1}\right)$. Green bar: oxygen evolution rate, yellow bar: oxygen consumption rate. Error bars indicate the SE based on at least three independent experiments.

\section{RESULTS}

\section{Growth and Photosynthetic Activity of E. gracilis Under Different Growth Conditions}

Euglena gracilis cells were grown under different growth conditions, namely photoautotrophic (CM: CM medium, $100 \mu \mathrm{mol}$ photons $\left.\mathrm{m}^{-2} \mathrm{~s}^{-1}\right)$, photomixotrophic $(\mathrm{CM}+\mathrm{Glc}$ : 


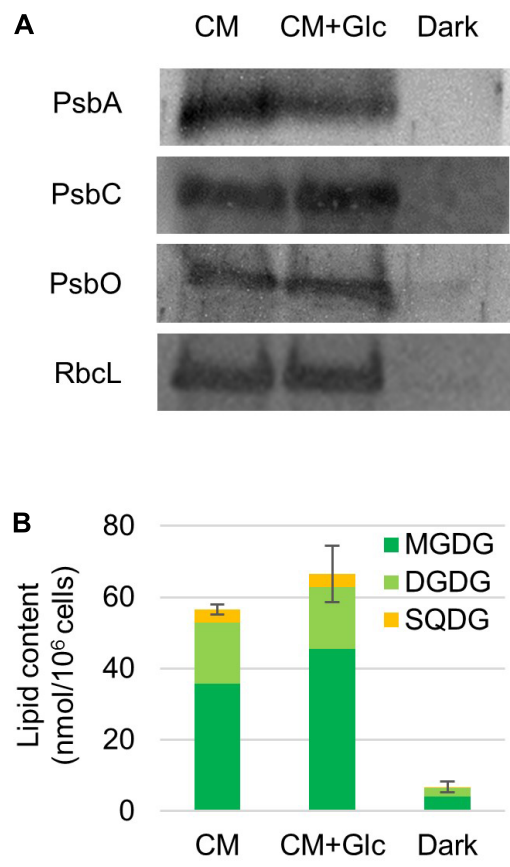

FIGURE 2 | Photosynthetic protein and thylakoid glycolipid levels in cells grown under photoautotrophic, photomixotrophic and heterotrophic conditions. (A) Western blot analysis of photosynthetic proteins. Antibodies used are indicated on the left. (B) Thylakoid glycolipid content. Error bar shows SE $(n=3)$ of the total amount of glycolipids.

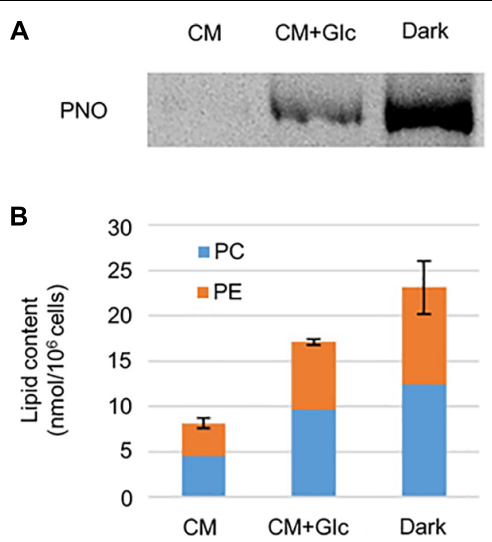

FIGURE 3 | Mitochondrial protein and phospholipid levels in cells grown under photoautotrophic, photomixotrophic and heterotrophic conditions. (A) Western blot analysis of a mitochondrion protein, PNO. (B) Phospholipid content. Error bar shows SE $(n=3)$ of total amount of two extraplastidic phospholipids, PC and PE.

CM medium with $0.6 \%$ glucose, $100 \mu \mathrm{mol}$ photons $\mathrm{m}^{-2} \mathrm{~s}^{-1}$ ) and heterotrophic (Dark: CM medium with $0.6 \%$ glucose, dark) conditions. First, growth rates of E. gracilis cells in each condition were compared. As shown in Figure 1A, the cells grew at similar rates under all conditions and the Dark condition showed the highest cell number compared with the others. Chlorophyll content was almost the same among cells grown in CM and

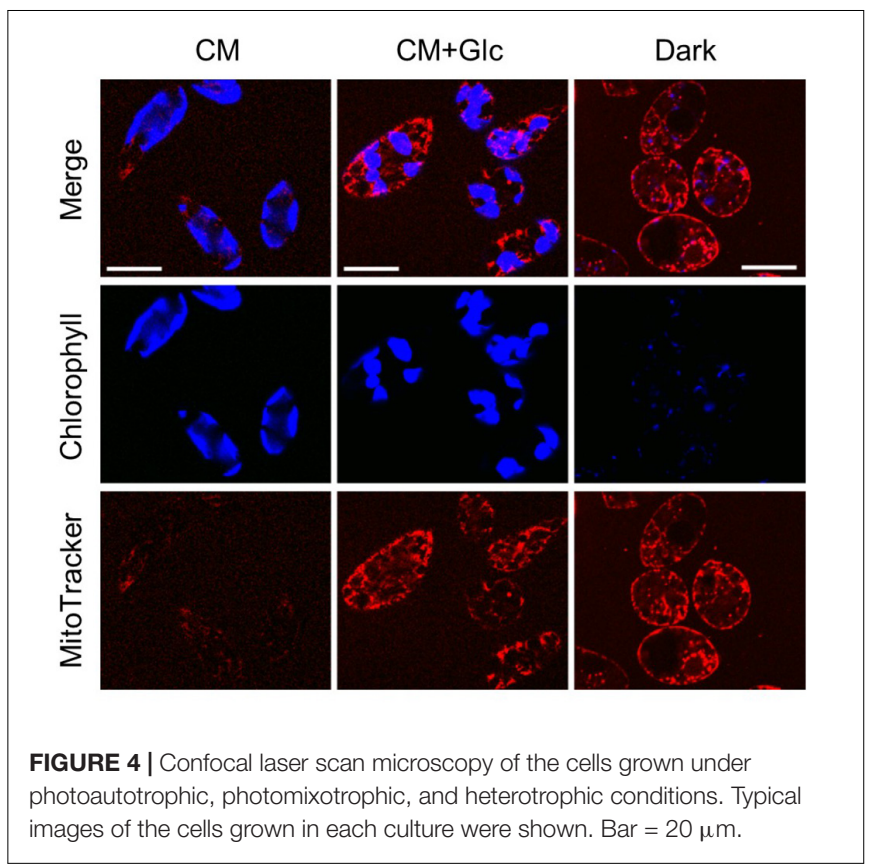

$\mathrm{CM}+$ Glc media [chlorophyll (Chl) $a+b$ per $10^{6}$ cells $\pm \mathrm{SE}$, $n \geq 12: \mathrm{CM}, 23.30 \pm 0.75 \mu \mathrm{g} \mathrm{Chl;} \mathrm{CM+Glc,} 23.22 \pm 1.20 \mu \mathrm{g} \mathrm{Chl]}$ (Figure 1B). On the other hand, in Dark conditions, chlorophyll content was much lower than in the cells illuminated by light (1.25 $\pm 0.28 \mu \mathrm{g}$ Chl). We next analyzed oxygen evolution rate in the cells. As expected from the lower Chl contents, oxygen consumption was observed in the cells cultured in Dark conditions even under light (Figure 1C). This consumption rate was slightly lower than the oxygen consumption rate measured under dark conditions (respiration), indicating that the darkgrown cells still have a weak photosynthetic activity. Cells grown under CM conditions showed a higher oxygen evolution rate compared with the cells grown under $\mathrm{CM}+\mathrm{Glc}$ conditions. This can be explained by a higher rate of oxygen consumption in the cells of $\mathrm{CM}+\mathrm{Glc}$ conditions (Figure 1C). In fact, the total amount of oxygen evolution/consumption was almost the same in the cells grown in $\mathrm{CM}$ and $\mathrm{CM}+\mathrm{Glc}$ conditions (CM, $9.48 \mathrm{nmol} / \mathrm{s} / 10^{6}$ cells; $\mathrm{CM}+\mathrm{Glc}, 9.53 \mathrm{nmol} / \mathrm{s} / 10^{6}$ cells). These results suggest that cells grown under light have similar photosynthetic activities, but addition of glucose stimulated respiration activity in the cells grown in $\mathrm{CM}+\mathrm{Glc}$ conditions. The protein content of the cells was also analyzed (protein per $10^{6}$ cells \pm SE, $n=3:$ CM, $269.63 \pm 17.87 \mu$ g Protein; CM+Glc, $253.06 \pm 9.93 \mu \mathrm{g}$ Protein; Dark, $200.61 \pm 11.13 \mu \mathrm{g}$ Protein). Dark-grown cells had less proteins than others but still to the same extent. Compositional changes in the protein profile were shown using a CBB-stained acrylamide gel (Supplementary Figure S1).

\section{Chloroplast Development in Illuminated E. gracilis Cells}

It was expected from the above-mentioned results that chloroplasts are developed under light regardless of the 
carbon source $\left(\mathrm{CO}_{2}\right.$ or $\left.\mathrm{CO}_{2}+\mathrm{Glc}\right)$. To confirm this finding, we analyzed protein levels of photosynthetic complexes and thylakoid lipids. First, photosynthetic proteins, namely proteins from PSII [PsbA/D (D1/D2), PsbC (CP43) and PsbO] and the Rubisco large subunit were analyzed. As shown in Figure 2, these proteins were abundant in the cells grown under light (CM and $\mathrm{CM}+\mathrm{Glc}$ conditions). On the other hand, these proteins were less abundant in the cells grown under Dark conditions.

We then analyzed the amount of thylakoid lipids in the cells grown under each condition. The major lipids in the thylakoid membranes are MGDG, DGDG, SQDG, and PG (Kobayashi et al., 2016). However, PG is also found in other membrane system such as the ER and mitochondria. We analyzed the amount of the glycolipids, namely MGDG, DGDG, and SQDG. Galactolipids MGDG and DGDG accumulated to high levels in the cells grown in both $\mathrm{CM}$ and $\mathrm{CM}+\mathrm{Glc}$ conditions. Together with SQDG, the total amounts of glycolipids were $56.58 \pm 1.36 \mathrm{nmol} / 10^{6}$ cells in $\mathrm{CM}$ conditions and $66.55 \pm 7.89 \mathrm{nmol} / 10^{6}$ cells in $\mathrm{CM}+\mathrm{Glc}$ conditions. In contrast, in Dark conditions, the amount of glycolipids was about ten times lower $\left(6.80 \pm 1.48 \mathrm{nmol} / 10^{6}\right.$ cells), indicating that the thylakoid membrane was not developed well in dark-grown cells. We also analyzed the quantum efficiency of PSII, yet this could not be detected in the cells grown in Dark conditions. This is probably because there are not enough PSII proteins, such as PsbA/D, $\mathrm{PsbC}$, and PsbO (Figure 2A). Conversely, the cells grown under light showed similar efficiencies regardless of carbon source (CM condition, $0.66 \pm 0.01 ; \mathrm{CM}+\mathrm{Glc}$ conditions, $0.62 \pm 0.02)$. These results suggest that $E$. gracilis grown under light accumulated proteins of photosynthetic complexes and thylakoid glycolipids to construct active thylakoid membranes.

\section{Mitochondria Development in E. gracilis Under Heterotrophic Conditions}

As shown in Figure 2, respiration rate increased under heterotrophic conditions. To monitor whether the E. gracilis cells developed mitochondria in those conditions, we analyzed mitochondrial protein content. We used an antibody against pyruvate: NADP+ oxidoreductase (PNO) which is involved in the formation of acetyl-CoA and localizes in mitochondria

TABLE 1 | Glycerolipid content of E. gracilis cells grown under photoautotrophic, photomixotrophic and heterotrophic conditions.

\begin{tabular}{lcrr}
\hline & \multicolumn{1}{c}{$\mathbf{C M}$} & $\mathbf{C M}+\mathbf{G l c}$ & \multicolumn{1}{c}{ Dark } \\
\hline MGDG & $35.73 \pm 2.11$ & $45.46 \pm 6.93$ & $4.11 \pm 0.99$ \\
DGDG & $17.22 \pm 0.69$ & $17.38 \pm 1.27$ & $2.33 \pm 0.41$ \\
SQDG & $3.63 \pm 0.11$ & $3.71 \pm 0.42$ & $0.35 \pm 0.09$ \\
PG & $2.94 \pm 0.10$ & $2.67 \pm 0.08$ & $0.47 \pm 0.15$ \\
PC & $4.54 \pm 0.34$ & $9.64 \pm 0.52$ & $12.40 \pm 0.80$ \\
PE & $3.58 \pm 0.32$ & $7.44 \pm 0.39$ & $10.71 \pm 2.14$ \\
PI & $0.37 \pm 0.04$ & $0.61 \pm 0.07$ & $0.40 \pm 0.08$ \\
others & $2.83 \pm 0.33$ & $3.25 \pm 0.23$ & $1.95 \pm 0.29$ \\
TAG & $0.39 \pm 0.06$ & $1.58 \pm 0.65$ & $2.85 \pm 0.53$ \\
\hline
\end{tabular}

Values are $n$ mol/ $10^{6}$ cells $\pm S E(n=3)$.

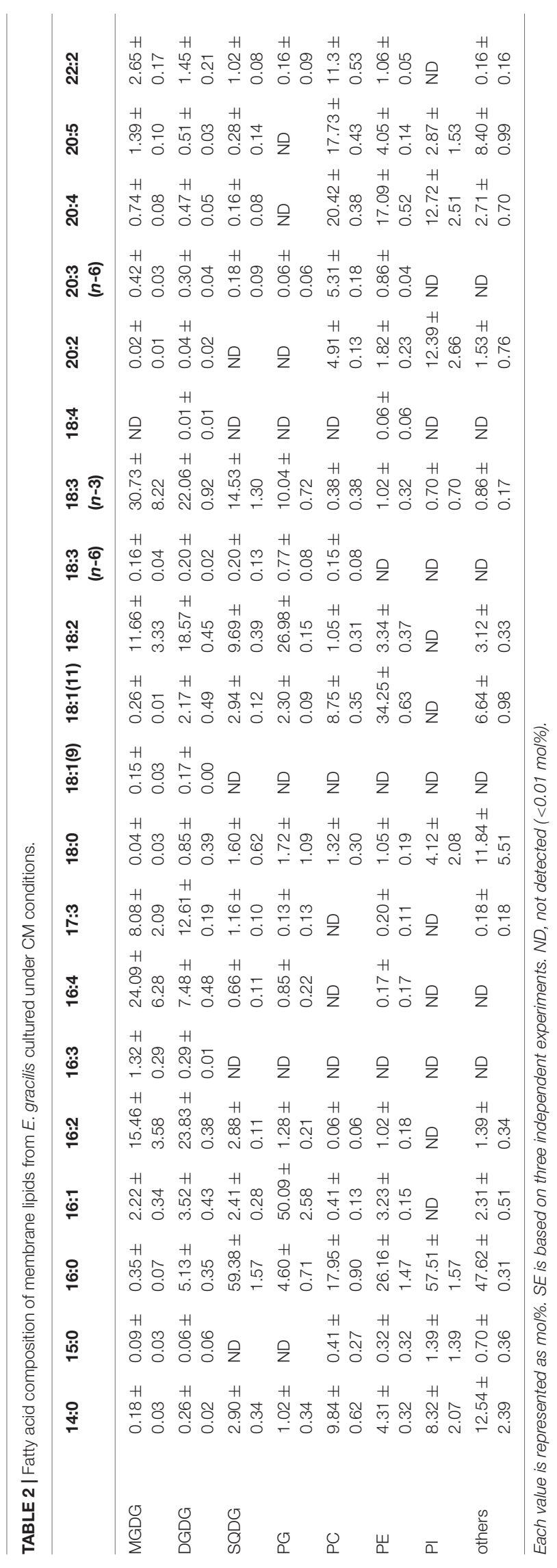




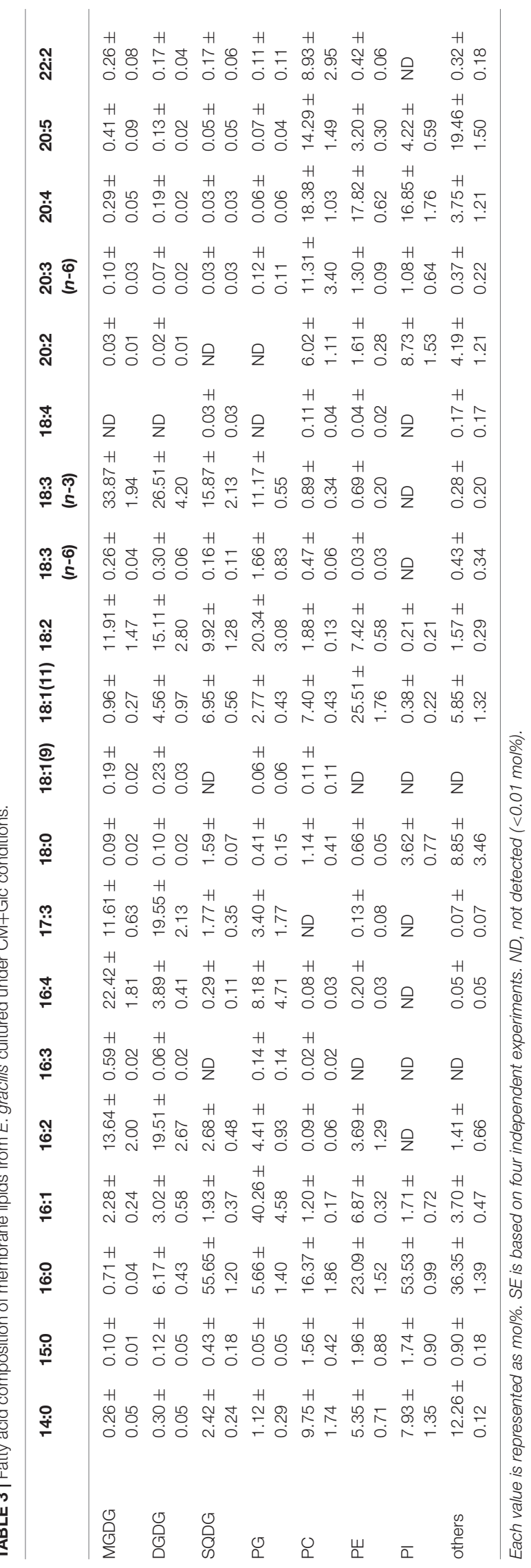

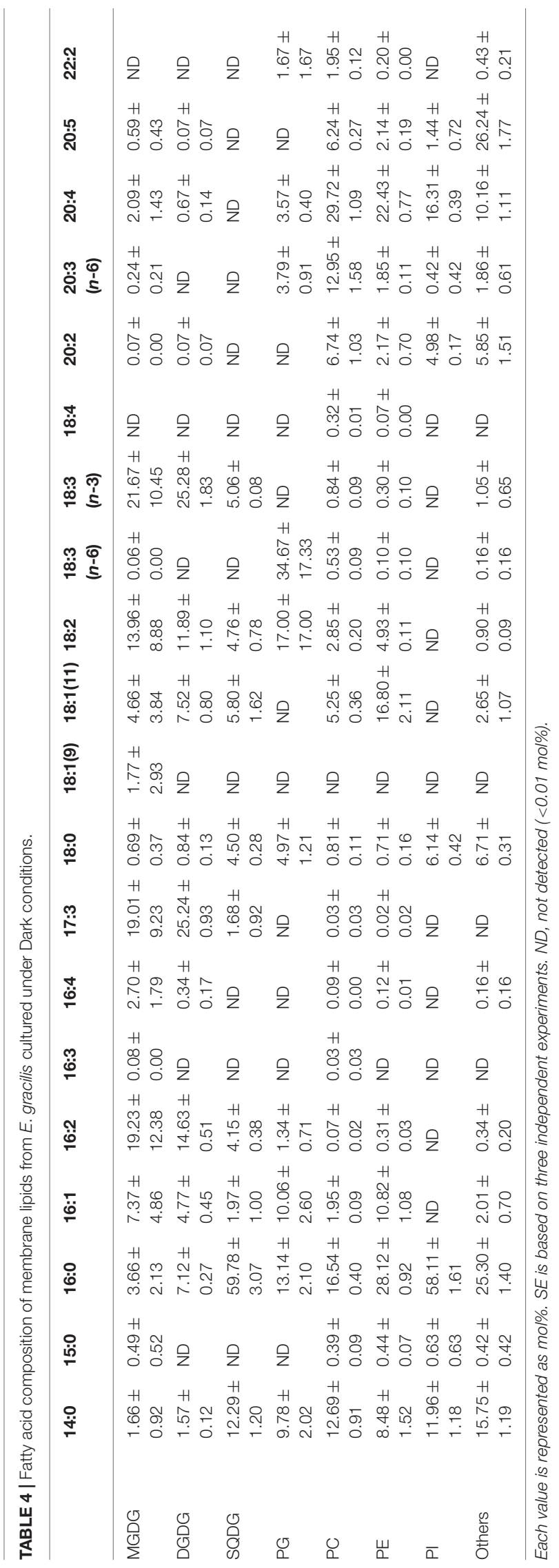




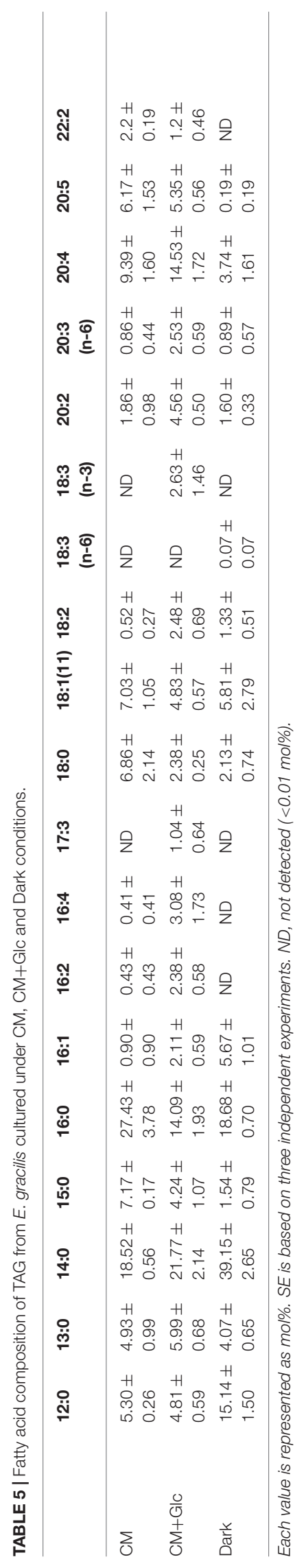

(Nakazawa et al., 2017). As expected, under heterotrophic conditions, E. gracilis cells accumulated PNO compared to the cells grown under CM conditions (Figure 3A). We also detected $\mathrm{PNO}$ in the cells grown under $\mathrm{CM}+\mathrm{Glc}$ conditions, but it was less than that of the Dark conditions.

We next analyzed content of phospholipids, PC, and PE, which are typical membrane lipids in mitochondria. As shown in Figure 3B, the amounts of these lipids were highest in the cells grown under Dark conditions $\left(23.12 \pm 2.93 \mathrm{nmol} / 10^{6}\right.$ cells). The cells grown under $\mathrm{CM}+\mathrm{Glc}$ conditions had fewer lipids $\left(17.08 \pm 0.36 \mathrm{nmol} / 10^{6}\right.$ cells $)$ than the cells grown in the dark, but still more than twice as much as the cells grown under $\mathrm{CM}$ conditions $\left(8.12 \pm 0.56 \mathrm{nmol} / 10^{6}\right.$ cells). Together with the respiration rate and amount of PNO, these results suggest that mitochondria are well developed when a carbon source is added to the medium.

To confirm these phenomena, we observed the cells grown under each condition using a confocal laser scanning microscope. As shown in Figure 4, auto-fluorescence of chlorophyll (indicated by blue) was seen clearly in the cells grown under light (CM and $\mathrm{CM}+\mathrm{Glc}$ conditions). The cells grown in Dark conditions showed faint signal of chlorophyll, correlate with the chlorophyll content of the cells (Figure 1B). Mitochondria were stained using MitoTracker and indicated by pink. The cells grown with glucose $(\mathrm{CM}+\mathrm{Glc}$ and Dark conditions) showed strong signals of MitoTracker compared with the cells grown under $\mathrm{CM}$ conditions, which also correlate with the respiration activity; contents of PNO and phospholipids. These results agree with the idea that lipid contents correlated with chloroplasts and mitochondria development.

\section{Revisiting Lipid and Fatty Acid Contents of E. gracilis}

Lipid content of E. gracilis is summarized in Table 1. We detected seven membrane lipids as major constituents, including three glycolipids (MGDG, DGDG, and SQDG) and four phospholipids (PC, PE, PG, and PI). This composition is very similar to the lipid content of other eukaryotic phototrophs, such as the model dicot Arabidopsis thaliana (Browse et al., 1986). According to the fatty acid base calculation, we succeeded in detecting more than $94 \mathrm{~mol} \%$ of membrane lipids in E. gracilis. The other $6 \mathrm{~mol} \%$ of membrane lipids (others in Table 1) could not be determined because they did not co-migrate with the available standards, such as sphingomyelin or phosphatidylserine and were difficult to analyze by LC-MS/MS because of their low abundancies.

Fatty acid contents of each membrane lipid in the different growth conditions are described in Tables 2-4. The fatty acid content was similar regardless of growth conditions, except for PG. PG in the cells grown under Dark condition had much more $\gamma$-linolenic acid [18:3(n-6)] compared to the cells grown under $\mathrm{CM}$ or $\mathrm{CM}+\mathrm{Glc}$ conditions [more $\alpha$-linolenic acid: 18:3(n-3)]. Thylakoid galactolipids, namely MGDG and DGDG, were found to have more hexadeca-4,7,10,13-tetraenoic acid (16:4). Phospholipids such as PC and PE contained more of the long chain fatty acid, eicosatetraenoic acid (20:4). 
TABLE 6 | List of genes encoding homologs of thylakoid glycolipid synthases found in RNAseq data.

\begin{tabular}{|c|c|c|}
\hline Genes & Function & Comp number in the RNAseq data \\
\hline \multirow[t]{2}{*}{ MGD1 } & Galactosyltransferase for MGDG synthesis (plant type) & comp33364_c0_seq1 \\
\hline & & comp31220_c0_seq1 \\
\hline \multirow[t]{2}{*}{ DGD1 } & Galactosyltransferase for DGDG synthesis (plant type) & comp33692_c1_seq1 \\
\hline & & comp27690_c0_seq1 \\
\hline \multirow[t]{2}{*}{ SQD2 } & Sulfoquinovosyltransferase for SQDG synthesis & comp34481_c0_seq2 \\
\hline & & comp21910_c0_seq1 \\
\hline
\end{tabular}

The sequence data are available at the DDBJ Sequence Read Archive (DRA) with accession number SRP060591.

We also analyzed the abundancy of triacylglycerol (TAG) (Table 1), which is another storage lipid. The amount of TAG per cell increased when Glc was added to the medium, and TAG was highest in the cells grown under Dark conditions. This TAG had short chain saturated fatty acids, such as lauric acid 12:0, 14:0, and 16:0 as the major components (Table 5). On the other hand, the cells grown under $\mathrm{CM}$ or $\mathrm{CM}+\mathrm{Glc}$ conditions had fewer short chain saturated fatty acids and more long chain fatty acids (20:4).

\section{DISCUSSION}

\section{E. gracilis Uses Plant-Type Pathways for Galactolipid Synthesis}

Euglenoids are believed to acquire chloroplasts through secondary endosymbiosis. We found that, under illumination, E. gracilis cells accumulated thylakoid glycolipids, especially two galactolipids, MGDG and DGDG. These galactolipids can be found in all oxygenic phototrophs and are known to be synthesized by two pathways, the plant-type pathway and cyanobacteria-type pathway (Awai, 2016). Some algae, such as primitive red algae and glaucophytes, are known to have the plant-type enzyme for MGDG synthesis and the cyanobacteriatype enzyme for DGDG synthesis (Awai et al., 2007; Sakurai et al., 2007; Hori et al., 2016; Maida and Awai, 2016; Sato and Awai, 2016). We analyzed whether the chloroplast glycolipids in $E$. gracilis are synthesized by the plant-type enzymes using EST data (Yoshida et al., 2016). As expected, the genes encoding plant-type enzymes for galactolipid synthesis were found (Table 6), as green algae utilize plant-type enzymes for both MGDG and DGDG synthesis. The SQDG synthetic pathway is basically conserved from cyanobacteria to plants, and E. gracilis was found to use the same system. We also tried to analyze the synthetic pathways for phospholipids determined by our analysis, but it was too complicated to be analyzed since euglenoids seem to have pathways from both the host cell and engulfed cell of the secondary symbiosis. Genomic sequencing analysis will be required to solve whole lipid synthetic pathway in E. gracilis.

\section{Possible Application for Bioengineering by Controlling Flow of Fatty Acid Metabolism}

The production of biofuel for sustainable energy is highly anticipated as a next generation energy source for ecological and economic reasons (Chisti, 2007; Kraan, 2013). E. gracilis is a strong candidate for the production of such energy because of its ability to produce wax ester, which can exceed $40 \%$ of its dry weight (Inui et al., 1983). Wax ester in E. gracilis is synthesized from fatty acid and fatty alcohol mainly by WSD-type wax synthase (Tomiyama et al., 2017). This wax ester is suitable for bioenergy, because of their relatively short chained (C14) fatty acids and alcohols. Since the synthesis of membrane lipids and TAG also require fatty acids, it is important to know how the fatty acid flow and channel for synthesis of wax ester or glycerolipids. Our study described here provides details on how much glyceorolipids are synthesized in E. gracilis grown in photoautotrophic, photomixotrophic, and heterotrophic conditions. These data will inform the manipulation of fatty acid flow between glycerolipids and wax ester. We observed the accumulation of short chain fatty acid, especially 14:0 in TAG from cells grown under heterotrophic conditions. The major fatty acid of wax ester in E. gracilis is also 14:0, and TAG will be a target to enhance wax ester accumulation.

Recently, a photoenzyme which converts fatty acids to hydrocarbons was found in green algae (Sorigue et al., 2017). Using the amino acid sequence of this enzyme as a bait, we did a BLAST search of an Euglena EST database and found its homologs belonging to the GMC oxidoreductase super family (comp29747_c0_seq1: Expect $=6 \mathrm{e}-80$ and comp30342_c0_seq1: Expect $=5 \mathrm{e}-40)$. However, enzymes of this family more closely resemble bacterial choline dehydrogenase, not the hydrocarbon synthase of green algae, implying that E. gracilis do not possess such enzymes for alkane synthesis. E. gracilis has the capacity to accumulate wax ester, and it is likely that it can be switch to synthesize alkene. Recently, a method for introduction of transgenes has been established in E. gracilis (Ogawa et al., 2015). It will be interesting to see if we can introduce this photoenzyme to E. gracilis with regulated fatty acid flow for another type of biofuel production in E. gracilis.

\section{AUTHOR CONTRIBUTIONS}

SS, TI, and KA conceived the research. SS and S-iA conducted the experiments. SS, S-iA, TI, and KA performed the data analysis and wrote the manuscript.

\section{FUNDING}

This work was supported in part by grants, Precursory Research for Embryonic Science and Technology, from the Japan Science 
and Technology Agency to S-iA, and Core Research for Evolutional Science and Technology, from the Japan Science and Technology Agency to TI and KA.

\section{ACKNOWLEDGMENTS}

The authors are grateful to Dr. Masahiko Ikeuchi and Dr. Masami Nakazawa for their gift of anti-PsbA and anti-PNO antibodies, respectively.

\section{REFERENCES}

Allen, C. F., Good, P., Davis, H. F., Chisum, P., and Fowler, S. D. (1966). Methodology for the separation o plant lipids and application to spinach leaf and chloroplast lamellae. J. Am. Oil Chem. Soc. 43, 223-231. doi: 10.1007/ bf02641091

Arnon, D. I. (1949). Copper enzymes in isolated chloroplasts. Polyphenoloxidase in Beta vulgaris. Plant Physiol. 24, 1-15. doi: 10.1104/pp.24.1.1

Awai, K. (2016). Thylakoid development and galactolipid synthesis in cyanobacteria. Subcell. Biochem. 86, 85-101. doi: 10.1007/978-3-31925979-6_4

Awai, K., Ohta, H., and Sato, N. (2014). Oxygenic photosynthesis without galactolipids. Proc. Natl. Acad. Sci. U.S.A. 111, 13571-13575. doi: 10.1073/pnas. 1403708111

Awai, K., Watanabe, H., Benning, C., and Nishida, I. (2007). Digalactosyldiacylglycerol is required for better photosynthetic growth of Synechocystis sp. PCC6803 under phosphate limitation. Plant Cell Physiol. 48, 1517-1523. doi: 10.1093/pcp/pcm134

Barthel, S., Bernat, G., Seidel, T., Rupprecht, E., Kahmann, U., and Schneider, D. (2013). Thylakoid membrane maturation and PSII activation are linked in greening Synechocystis sp. PCC 6803 cells. Plant Physiol. 163, 1037-1046. doi: $10.1104 /$ pp. 113.224428

Bligh, E. G., and Dyer, W. J. (1959). A rapid method of total lipid extraction and purification. Can. J. Biochem. Physiol. 37, 911-917. doi: 10.1139/y59-099

Browse, J., Warwick, N., Somerville, C. R., and Slack, C. R. (1986). Fluxes through the prokaryotic and eukaryotic pathways of lipid synthesis in the '16:3' plant Arabidopsis thaliana. Biochem. J. 235, 25-31. doi: 10.1042/bj2350025

Calvayrac, R., and Douce, R. (1970). Les polyglycerophospholipides d'Euglena gracilis. FEBS Lett. 7, 259-262. doi: 10.1016/0014-5793(70)80175-2

Chisti, Y. (2007). Biodiesel from microalgae. Biotechnol. Adv. 25, 294-306. doi: 10.1016/j.biotechadv.2007.02.001

Constantopoulos, G., and Bloch, K. (1967). Effect of light intensity on the lipid composition of Euglena gracilis. J. Biol. Chem. 242, 3538-3542.

Cramer, M., and Myers, J. (1952). Growth and photosynthetic characteristics of Euglena gracilis. Arch. Mikrobiol. 17, 384-402. doi: 10.1007/bf00410835

Ferroni, L., Baldisserotto, C., Pantaleoni, L., Fasulo, M. P., Fagioli, P., and Pancaldi, S. (2009). Degreening of the unicellular alga Euglena gracilis: thylakoid composition, room temperature fluorescence spectra and chloroplast morphology. Plant Biol. 11, 631-641. doi: 10.1111/j.1438-8677.2008. 00152.x

Fujita, T., Matsuda, H., Sato, T., Iwasaki, T., and Takafuji, S. I. (1995). Phospholipid composition and phospholipase activity of Euglena. J. Japan Oil Chem. Soc. 44, 197-202. doi: 10.5650/jos1956.44.197

Gibbs, S. P. (1978). The chloroplasts of Euglena may have evolved from symbiotic green algae. Can. J. Bot. 56, 2883-2889. doi: 10.1139/b78-345

Hölzl, G., Zahringer, U., Warnecke, D., and Heinz, E. (2005). Glycoengineering of cyanobacterial thylakoid membranes for future studies on the role of glycolipids in photosynthesis. Plant Cell Physiol. 46, 1766-1778. doi: 10.1093/pcp/pci189

Hori, K., Nobusawa, T., Watanabe, T., Madoka, Y., Suzuki, H., Shibata, D., et al. (2016). Tangled evolutionary processes with commonality and diversity in plastidial glycolipid synthesis in photosynthetic organisms. Biochim. Biophys. Acta 1861, 1294-1308. doi: 10.1016/j.bbalip.2016.04.015

Hulanicka, D., Erwin, J., and Bloch, K. (1964). Lipid metabolism of Euglena gracilis. J. Biol. Chem. 239, 2778-2787.

\section{SUPPLEMENTARY MATERIAL}

The Supplementary Material for this article can be found online at: https://www.frontiersin.org/articles/10.3389/fpls.2018.00370/ full\#supplementary-material

FIGURE S1 | SDS-PAGE of E. gracilis proteins. Proteins were extracted from cells grown under photoautotrophic, photomixotrophic and heterotrophic conditions and subjected to SDS-PAGE followed by CBB staining. Lane 1, CM conditions; lane 2, CM+Glc conditions; lane 3, Dark conditions. M: molecular weight marker (Nacalai Tesque, Inc.).

Inui, H., Ishikawa, T., and Tamoi, M. (2017). Wax ester fermentation and its application for biofuel production. Adv. Exp. Med. Biol. 979, 269-283. doi: 10.1007/978-3-319-54910-1_13

Inui, H., Miyatake, K., Nakano, Y., and Kitaoka, S. (1982). Wax ester fermentation in Euglena gracilis. FEBS Lett. 150, 89-93. doi: 10.1016/0014-5793(82)81310-0

Inui, H., Miyatake, K., Nakano, Y., and Kitaoka, S. (1983). Production and composition of wax esters by fermentation of Euglena gracilis. Agric. Biol. Chem. 47, 2669-2671. doi: 10.1080/00021369.1983.10866013

Inui, H., Miyatake, K., Nakano, Y., and Kitaoka, S. (1984). Fatty acid synthesis in mitochondria of Euglena gracilis. Eur. J. Biochem. 142, 121-126. doi: 10.1111/j. 1432-1033.1984.tb08258.x

Kalscheuer, R., and Steinbuchel, A. (2003). A novel bifunctional wax ester synthase/acyl-CoA:diacylglycerol acyltransferase mediates wax ester and triacylglycerol biosynthesis in Acinetobacter calcoaceticus ADP1. J. Biol. Chem. 278, 8075-8082. doi: 10.1074/jbc.M210533200

Kobayashi, K., Endo, K., and Wada, H. (2016). "Roles of lipids in photosynthesis," in Lipids in Plant and Algae Development, eds Y. Nakamura and Y. Li-Beisson (Cham: Springer International Publishing), 21-49.

Kraan, S. (2013). Mass-cultivation of carbohydrate rich macroalgae, a possible solution for sustainable biofuel production. Mitig. Adapt. Strateg. Glob. Change 18, 27-46. doi: 10.1007/s11027-010-9275-5

Laemmli, U. K. (1970). Cleavage of structural proteins during the assembly of the head of bacteriophage T4. Nature 227, 680-685. doi: 10.1038/227680a0

Maida, E., and Awai, K. (2016). Digalactosyldiacylglycerol is essential in Synechococcus elongatus PCC 7942, but its function does not depend on its biosynthetic pathway. Biochim. Biophys. Acta 1861(9 Pt B), 1309-1314. doi: 10.1016/j.bbalip.2016.03.011

McFadden, G. I. (2001). Primary and secondary endosymbiosis and the origin of plastids. J. Phycol. 37, 951-959. doi: 10.1046/j.1529-8817.2001.01126.x

Nagaoka, N., Yamashita, A., Kurisu, R., Watari, Y., Ishizuna, F., Tsutsumi, N., et al. (2017). DRP3 and ELM1 are required for mitochondrial fission in the liverwort Marchantia polymorpha. Sci. Rep. 7:4600. doi: 10.1038/s41598-017-04886-0

Nakazawa, M., Hayashi, R., Takenaka, S., Inui, H., Ishikawa, T., Ueda, M., et al. (2017). Physiological functions of pyruvate:NADP+ oxidoreductase and 2oxoglutarate decarboxylase in Euglena gracilis under aerobic and anaerobic conditions. Biosci. Biotechnol. Biochem. 81, 1386-1393. doi: 10.1080/09168451. 2017.1318696

Nichols, B. W., and James, A. T. (1964). The lipids of plant storage tissue. Fette Seifen Anstrichmittel 66, 1003-1006. doi: 10.1002/lipi.19640661207

Ogawa, T., Furuhashi, T., Okazawa, A., Nakai, R., Nakazawa, M., Kind, T., et al. (2014). Exploration of polar lipid accumulation profiles in Euglena gracilis using LipidBlast, an MS/MS spectral library constructed in silico. Biosci. Biotechnol. Biochem. 78, 14-18. doi: 10.1080/09168451.2014.877826

Ogawa, T., Tamoi, M., Kimura, A., Mine, A., Sakuyama, H., Yoshida, E., et al. (2015). Enhancement of photosynthetic capacity in Euglena gracilis by expression of cyanobacterial fructose-1,6-/sedoheptulose-1,7-bisphosphatase leads to increases in biomass and wax ester production. Biotechnol. Biofuels 8:80. doi: 10.1186/s13068-015-0264-5

Okazaki, Y., Kamide, Y., Hirai, M. Y., and Saito, K. (2013). Plant lipidomics based on hydrophilic interaction chromatography coupled to ion trap time-of-flight mass spectrometry. Metabolomics 9(Suppl. 1), 121-131. doi: 10.1007/s11306011-0318-z

Osafune, T., Sumida, S., Ehara, T., Ueno, N., Hase, E., and Schiff, J. A. (1990). Lipid (wax) and Paramylum as Sources of Carbon and Energy for the Early 
Development of Proplastids in Dark-Grown Euglena gracilis Cells Transferred to an Inorganic Medium. J. Electron Microsc. 39, 372-381. doi: 10.1093/ oxfordjournals.jmicro.a050821

Regnault, A., Chervin, D., Chammai, A., Piton, F., Calvayrac, R., and Mazliak, P. (1995). Lipid composition of Euglena gracilis in relation to carbonnitrogen balance. Phytochemistry 40, 725-733. doi: 10.1016/0031-9422(95) 00268-C

Rosenberg, A. (1963). A comparison of lipid patterns in photosynthesizing and nonphotosynthesizing cells of Euglena gracilis. Biochemistry 2, 1148-1154. doi: 10.1021/bi00905a042

Rosenberg, A., Gouaux, J., and Milch, P. (1966). Monogalactosyl and digalactosyl diglycerides from heterotrophic, hetero-autotrophic, and photobiotic Euglena gracilis. J. Lipid Res. 7, 733-738.

Rosenberg, A., and Pecker, M. (1964). Lipid alterations in Euglena gracilis cells during light-induced greening. Biochemistry 3, 254-258. doi: 10.1021/ bi00890a019

Sakurai, I., Mizusawa, N., Wada, H., and Sato, N. (2007). Digalactosyldiacylglycerol is required for stabilization of the oxygen-evolving complex in photosystem II. Plant Physiol. 145, 1361-1370. doi: 10.1104/pp.107. 106781

Sato, N., and Awai, K. (2016). Diversity in biosynthetic pathways of galactolipids in the light of endosymbiotic origin of chloroplasts. Front. Plant Sci. 7:117. doi: $10.3389 /$ fpls.2016.00117

Scheer, A., and Parthier, B. (1982). Dark-induced chloroplast dedifferentiation in Euglena gracilis. Planta 156, 274-281. doi: 10.1007/BF003 93736

Schiff, J. A., and Schwartzbach, S. D. (1982). "Photocontrol of chloroplast development in euglena," in The Biology of Euglena Physiology, Vol. 3, D. E. Buetow (Cambridge, MA: Academic Press), 313-352.

Schwartzbach, S. D., Schiff, J. A., and Goldstein, N. H. (1975). Events surrounding the early development of Euglena chloroplasts. Plant Physiol. 63, 908-915.
Sorigue, D., Legeret, B., Cuine, S., Blangy, S., Moulin, S., Billon, E., et al. (2017). An algal photoenzyme converts fatty acids to hydrocarbons. Science 357, 903-907. doi: $10.1126 /$ science.aan6349

Sumida, S., Lyman, H., Kiyohara, N., and Osafune, T. (2007). Mechanism of conversion from heterotrophy to autotrophy in Euglena gracilis. Cytologia 72, 447-457. doi: 10.1508/cytologia.72.447

Suzuki, S., Awai, K., Ishihara, A., and Yamauchi, K. (2016). Cold temperature blocks thyroid hormone-induced changes in lipid and energy metabolism in the liver of Lithobates catesbeianus tadpoles. Cell Biosci. 6:19. doi: 10.1186/s13578016-0087-5

Tomiyama, T., Kurihara, K., Ogawa, T., Maruta, T., Ogawa, T., Ohta, D., et al. (2017). Wax ester synthase/diacylglycerol acyltransferase isoenzymes play a pivotal role in wax ester biosynthesis in Euglena gracilis. Sci. Rep. 7:13504. doi: 10.1038/s41598-017-14077-6

Yoshida, Y., Tomiyama, T., Maruta, T., Tomita, M., Ishikawa, T., and Arakawa, K. (2016). De novo assembly and comparative transcriptome analysis of Euglena gracilis in response to anaerobic conditions. BMC Genomics 17:182. doi: 10.1186/s12864-016-2540-6

Conflict of Interest Statement: The authors declare that the research was conducted in the absence of any commercial or financial relationships that could be construed as a potential conflict of interest.

The reviewer WR and handling Editor declared their shared affiliation.

Copyright $(\odot 2018$ Shibata, Arimura, Ishikawa and Awai. This is an open-access article distributed under the terms of the Creative Commons Attribution License (CC BY). The use, distribution or reproduction in other forums is permitted, provided the original author(s) and the copyright owner are credited and that the original publication in this journal is cited, in accordance with accepted academic practice. No use, distribution or reproduction is permitted which does not comply with these terms. 